\title{
TOWARDS 3D SMART CAMPUS VIA 3D CITY MODELLING
}

\author{
Ramlee, S.S.S., Abd Razak, N. *, Ujang, U., Mohd. Salleh, S., Azri, S., and Choon, T.L.
}

Geoinformation, Faculty of Built Environment and Surveying, Universiti Teknologi Malaysia (UTM), Johor, Malaysia sssuriati2@live.utm.my, fatihaarazak96@gmail.com, \{mduznir, suhaibah, tlchoon\}@utm.my, syahiirahsalleh78@gmail.com

KEY WORDS: Smart City, 3D GIS, Level of Details (LoD), Visualisation, 3D Modelling, Smart Campus System

\begin{abstract}
:
The smart city concept may aid in improving the city management, enhance the efficiency and thus increase the effectiveness of the city, where it is mainly focused on both information and technologies. This concept appears to be applicable for a smaller area such as university campus. Based on this idea, this research tries to implement the 3D smart campus for Universiti Teknologi Malaysia (UTM). This is an initial research towards a real implementation of 3D smart campus and conceivably 3D smart cities. This research focuses on the development of UTM smart campus by using 3D city modelling. The QGIS software was used to develop the 3D models. Then, the 3D model is viewed in a web browser for better 3D visualization and navigation. Furthermore, the results show that the 3D developed models for UTM smart campus can be a reliable platform to manage the spatial query and viewing the attributes of UTM campus buildings and facilities. This can be seen beneficial to the physical future development of the UTM campus area.
\end{abstract}

\section{3D SMART CAMPUS}

\subsection{Introduction}

The 3D smart campus as stated by Enqing et al. (2017) is the construction and development of digital campus, and the integrated environment of campus work, learning and living based on the internet of things. The completion of a few tasks are required in order to achieve the implementation and solve the problem of developing 3D smart campus. This includes developing the platform for data collection and data representation methods. Therefore, this research proposes 3D smart campus system via 3D city model to improve the quality of life and also solve the arising problems.

The rise of digital platform gives more advantages in the development of spatial data or other technologies to be created into virtual form. In most application fields, 3D modelling is also a means of obtaining quantitative subsurface models from which information can be gathered (Caumon et al., 2009). There are many advantages of $3 \mathrm{D}$ platform, but there also some issues that need to be of concern in maintaining the system. The visualisation via 3D GIS allows representation that is close to reality due to the selection of important aspects for imagination and evaluation (Köninger \& Bartel, 1998). It shows that 3D GIS map is very important for users to get the actual view of the location, especially the indoor view of the campus building.

In addition, Geographic Information System (GIS) can be used as tools for spatial data analysis and data management to solve problem such as finding the suitable classrooms capacity with number of student. Currently in UTM, students are unable to find the available classrooms that are match with the number of students at one time. This limitation will cause problems to students in planning their activities or programs that related to their courses. For instance, when making the room reservation, it is important to know the room availability. So, in this case, data such as room location, room capacity, person in charge for that room, and so on is required upon reservation. The data management is important in order to manage huge amount of information. Hence, the 3D smart campus system is the best platform to manage the spatial query and view the attributes of UTM campus buildings and facilities.

\subsection{Smart City Concept}

The smart city concept may help in improving the city management, enhance the efficiency and thus increase the effectiveness of the city, where it is mainly focused on both information and technologies (Batty et al., 2012). On top of that, there are many countries in the world have realized the importance of smart city and how the smart city idea would be advantageous for better organisation of cities.

According to Lee, Hancock, \& Hu (2014), the smart city that has been applied in the cities of many countries vary with their different coordination and mechanisms to control the development of the cities. The examples of countries that developed smart cities are Barcelona, Beijing, Singapore, Seoul, San Francisco, Italy and so on.

\subsection{UTM Smart Campus}

In this research, the UTM 3D smart campus model can be developed via 3D modelling. This will solve the problem faced by students and other people by providing them with the best presentation of $3 \mathrm{D}$ campus model for better understanding. Other than that, a functionality test was also carried out on the developed UTM 3D smart campus. By using the UTM 3D Smart Campus System, students and other people are able to make room reservations by knowing the room details correctly and also can get the actual view of UTM campus buildings.

\section{RESEARCH MOTIVATION}

This research focuses on the current issues and problems in spatial field. For example, there are services offered by UTM campus to help visitors to navigate in the campus but the services/system only enabled visitors to get the digital view of the campus (i.e. digital images and campus map). There is no representation of UTM campus that is close to reality. On the other hand, smart city concept has been developed in several 
cities around the globe for various purposes. It can be seen that the smart city concept can be implemented in campus environment since its gives many benefits to the campus system (Batty et al., 2012). The implementation of smart campus in UTM can be an initial start for a smart city implementation in Malaysia. Furthermore, the implementation of GIS in the campus can be used as tools for spatial data analysis and data management to solve problem such as finding the suitable classrooms capacity with number of students. Unfortunately, data depicted by a 2D map is not enough to represent the actual building structure (in 3D) and can lead to misleading information. The 2D data presented in the map together with the spatial attributes is insufficient without having the actual visualisation of the features.

Based on these, several questions raised such as 1) what are the requirements of 3D GIS towards 3D smart campus?, 2) how to implement 3D smart campus for UTM campus? and 3) how to validate the data management for the developed 3D smart campus system. Therefore, the aims of this research is to realize an initial 3D smart campus concept via implementing 3D city modelling as the base for spatial data management that is close to real representation of the UTM campus.

\section{METHODOLOGY}

Figure 1 shows the steps carried out in this research. The research activity as shown in Figure 1 consists of four phases

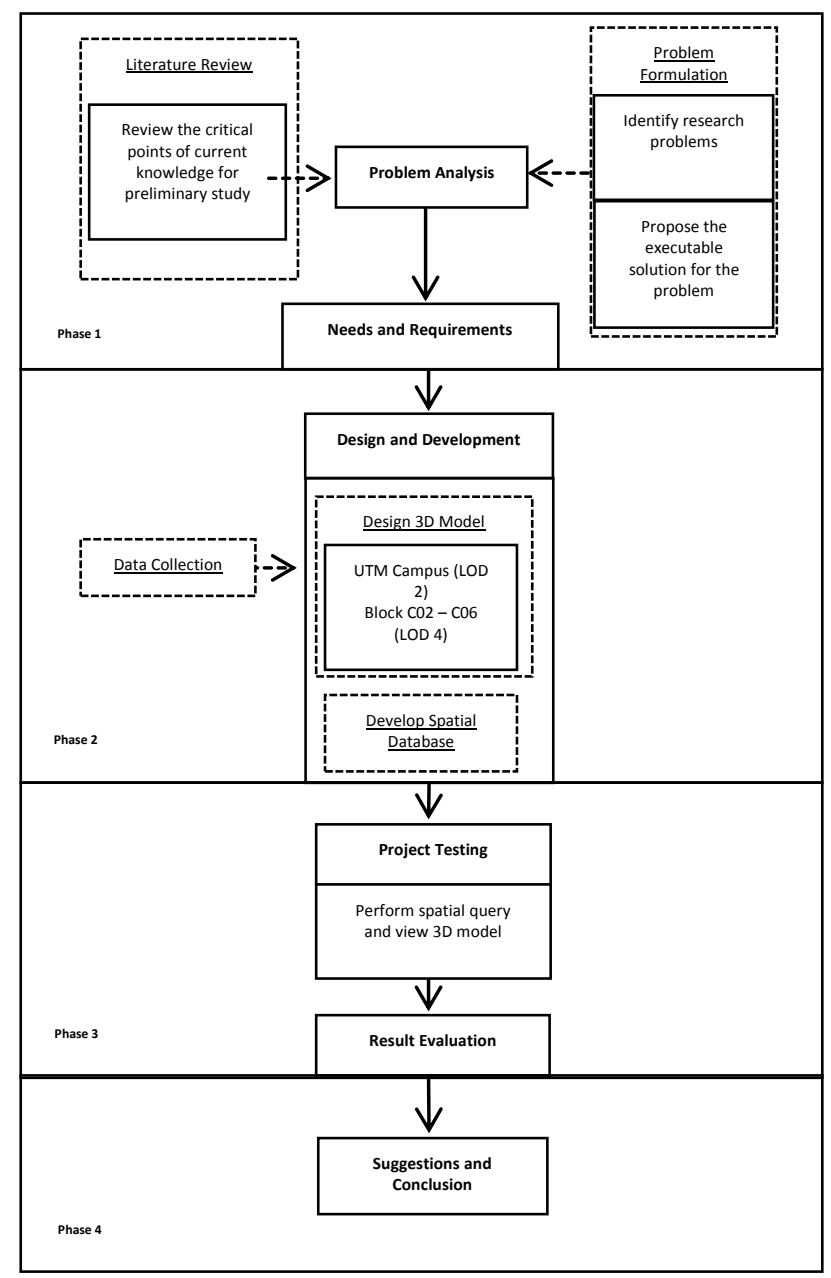

Figure 1. Research activities flow chart which are problem analysis phase, design and development phase, and project testing phase. In problem analysis phase, literature review was done to understand the current knowledge, to identify research problem and propose an executable solution for the problem. Design and development phase includes tasks such as design 3D model and develop spatial database for UTM campus. Next, project testing phase is carried out to perform spatial query and view 3D model.

\subsection{LODs of CITYGML 2.0}

UTM 3D smart campus models are designed based on the Level of Details (LOD) 4. LOD4 completes an LOD3 that adds openings, balconies, and including indoor features - furniture and other objects (Biljecki et al., 2016). While LOD2 is a more detailed model than LOD1, in which individual buildings are mandated, and are modelled as simple structures containing standard and simplified roof structures (see Figure 2).

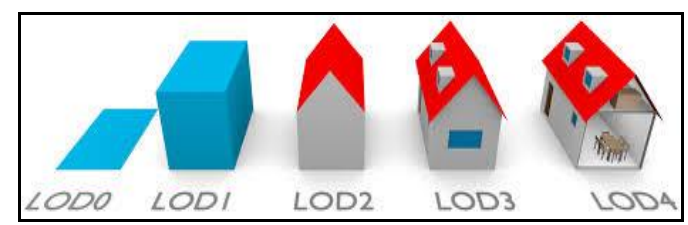

Figure 2. The five LODs of CityGML 2.0 (Biljecki et al., 2016)

\subsection{Development of 3D Model for UTM Campus}

The vector data are obtained from OpenStreetMap (OSM). The data later are processed using QGIS software using WGS84 as its coordinate reference system. The OSM layer is used as the 3D model basemap.

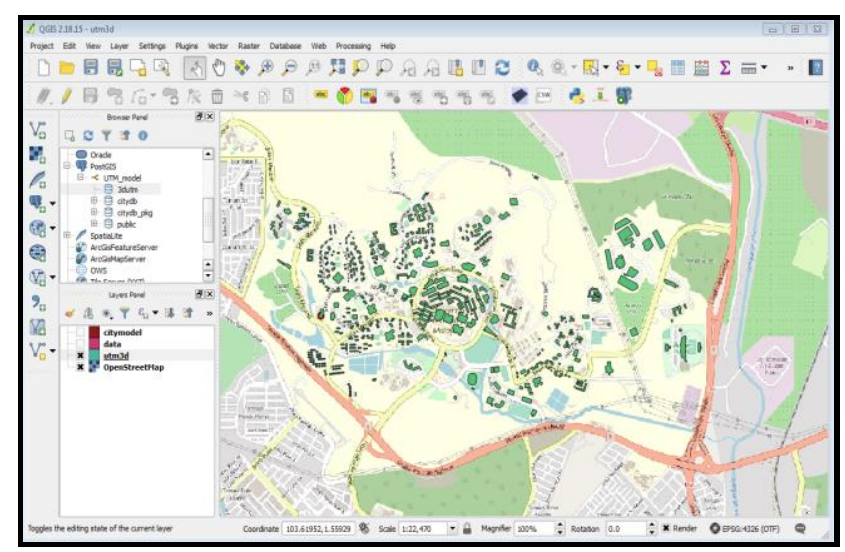

Figure 3. Data of UTM area downloaded from OSM

The Qgis2threejs plugin is a QGIS plugin, which visualises DEM data and vector data in $3 \mathrm{D}$ on web browsers. The plugin enabled the construction of various kinds of 3D objects with simple settings panels, view them in web view of exporter and generate files to publish them to web. 


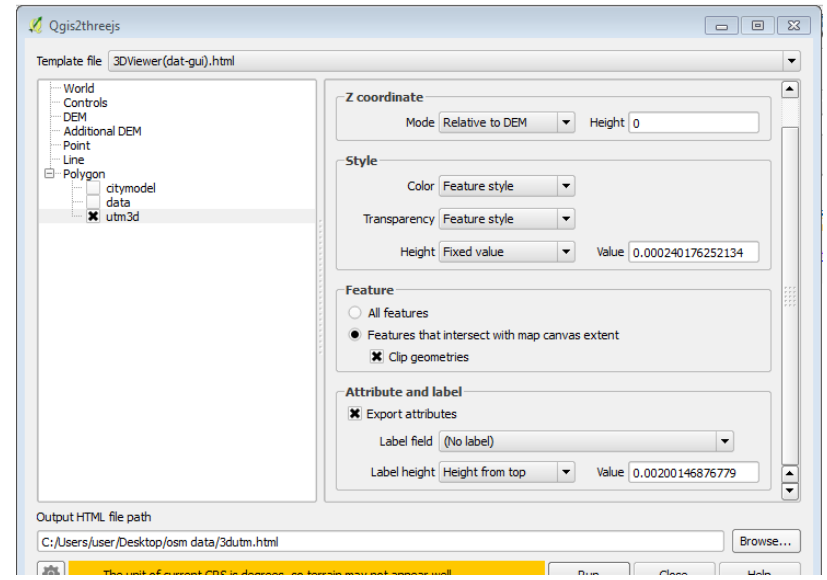

Figure 4. Qgis2Threejs plugins

\section{RESULTS AND DISCUSSION}

\subsection{D UTM Model}

The 3D model is realised using the geometrical characteristics and street view basemap (Figure 5). As a result, the information stored in the GIS database can be retrieved by clicking the building (Figure 6). In this way, the 3D model of UTM with all the useful information of each building could be used by any user or the people who access the data in web browser.

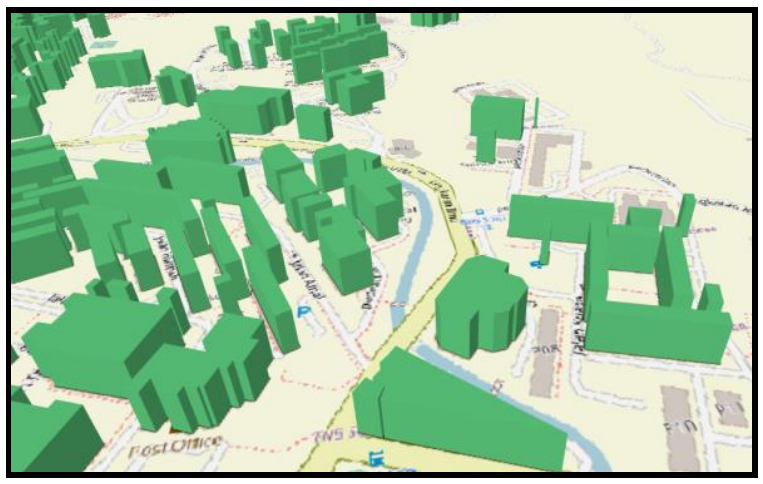

Figure 5. The view of 3D UTM campus in web browser

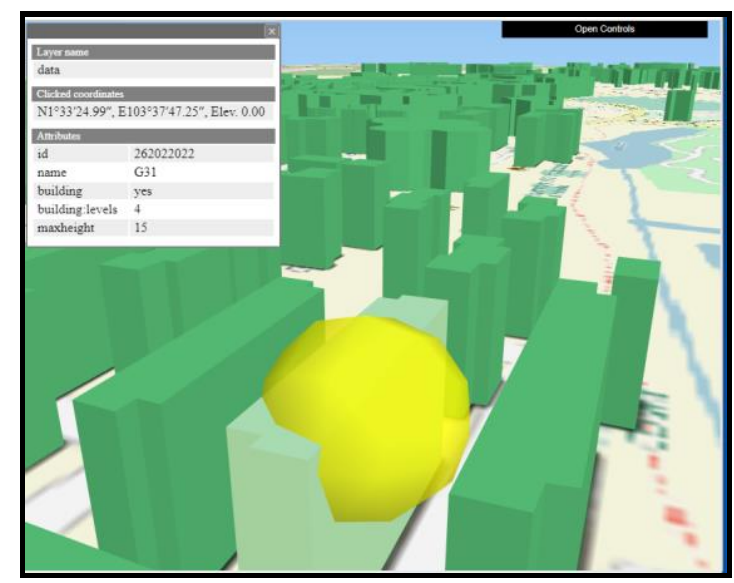

Figure 6. The view of 3D UTM model with attribute

In this way, the 3D UTM model presented in the web enables users to view the building. On top of that, users are able to access the building information anywhere just by having connection to the internet. In addition, users can view the building by zoom in, zoom out or rotating the map displayed in the web browser.

\subsection{Discussions}

There are challenges on creating 3D data such as the system need available data of studied area. The data must have coordinates to make sure that the building location is correct. Other than that, the software used must be able to read the data and transform the 2D data into 3D model. There are many open source GIS softwares that can be used to create 3D model such as SketchUp, AutoDesk Revit, QGIS, ArcScene and so on. Each of the software has strengths and weaknesses when developing the 3D model.

QGIS 2.18.15 used in this research able to generate the 3D model and visualised it in the web by using Qgis2Threejs plugin. The 3D representation is built by placing in the building height in the attribute of the data in the database. The generalisation of 3D model is based on the height in meters.

\section{CONCLUSION}

The model developed was able to visualise the 3D model and perform spatial query on the web platform. The 3D model of UTM was generated using QGIS 2.18.15 open source software and OSM data. Through this study, the 3D UTM model provides the information of buildings and can be used by user or students for searching and viewing the location of buildings or rooms.

3D models have become necessary to be implemented in many applications as it helps in better visualisation and analysis of an area. Furthermore, it can assist in the future development of the UTM campus area.

In this research, there are some aspects that can be explored to improve the model developed. The aspects are as follows; Data provided by OpenStreetMap are not complete and have null value. This will affect the information displayed in the 3D map. Therefore, future research should obtain latest data from administrator to integrate with OSM data. Next, UTM 3D smart campus can be improved by allowing users to make attribute query. In this system, users are only able to search the building by using single click on the building polygon. Then the details of the building are presented at the left side of the web page. An attribute query will be useful for future features or objects searching. Lastly, more studies can embark on other open source software that can be used to create 3D model such as SketchUp, AutoDesk Revit, QGIS, ArcScene and so on. These software supports the generation of 3D models from 2D map data.

\section{ACKNOWLEDGEMENTS}

This research was partially funded by UTM Research University Grant, Vot Q.J130000.3552.05G34 and Vot Q.J130000.3552.06G41. 


\section{REFERENCES}

Batty, M., Axhausen, K. W., Giannotti, F., Pozdnoukhov, A., Bazzani, A., Wachowicz, M., . . . Portugali, Y., 2012. Smart cities of the future. The European Physical Journal Special Topics, pp. 481-518.

Biljecki, F., Ledoux, H., \& Stoter, J., 2016. An improved LOD specification for 3D building models. Computers, Environment and Urban Systems, pp. 59, 25-37.

Caumon, G., Collon-Drouaillet, P., Veslud, C. L. C. d., Viseur, S., Sausse, J., 2009. Surface-Based 3DModeling of Geological Structures.

Enqing, J., Peixiang, R., Huanjin, W., \& Yanping, S., (2017). Discussion on Construction Method of Smart Campus basic Platform based on 3D Geographic Information Technology. $7790-7794$.

Köninger, A., Bartel, S., 1998. 3D-GIS for Urban Purposes. pp. 79- 103 .

Lee, J. H., Hancock, M. G., \& Hu, M.-C., 2014. Towards an effective framework for building smart cities: Lessons from Seoul and San Francisco. Technological Forecasting and Social Change, 89, pp. 80-99.

Revised August 2019 